\title{
Addition Reaction of Nitrones on the Reconstructed Si(100)-2×1 Surface
}

\author{
Yongjun Liu ${ }^{1,2 *}$ Zhiguo Wang ${ }^{1}$ \\ ${ }^{1}$ School of Chemistry and Chemical Engineering, Shandong University, Jinan, Shandong, 250100, China \\ ${ }^{2}$ Northwest Institute of Plateau Biology, Chinese Academy of Sciences, Xining,Qinghai, 810001, China
}

\section{Supporting Information}

\section{Computational method}

All calculations were carried out by using the Gaussian 98 program package. The hybrid density functional B3LYP with the 6-31G(d) basis sets were used for all DFT calculations.

\footnotetext{
* E-mail address: yongjunliu_1@ @sdu.edu.cn. Tel: 0531-88365576 Fax: 0531-88564464
} 


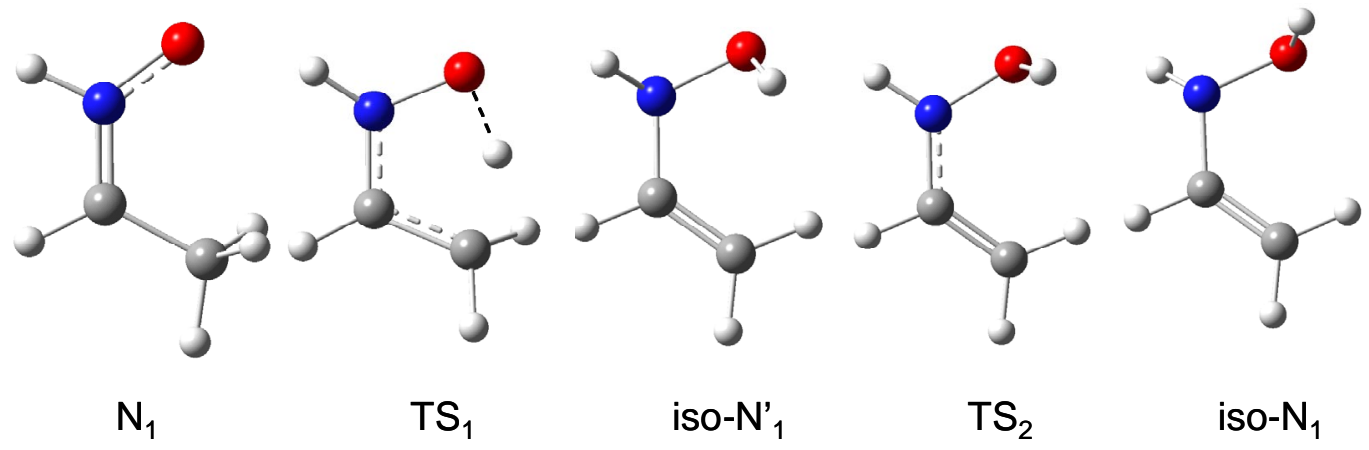

Figure $\mathrm{S} 1$ Optimized structures of nitrone $\left(\mathrm{N}_{1}\right)$, transition states $\left(\mathrm{TS}_{1}\right.$ and $\left.\mathrm{TS}_{2}\right)$ and its hydroxylamine tautomers (iso- $\mathrm{N}_{1}{ }_{1}$ and iso- $\mathrm{N}_{1}$ )

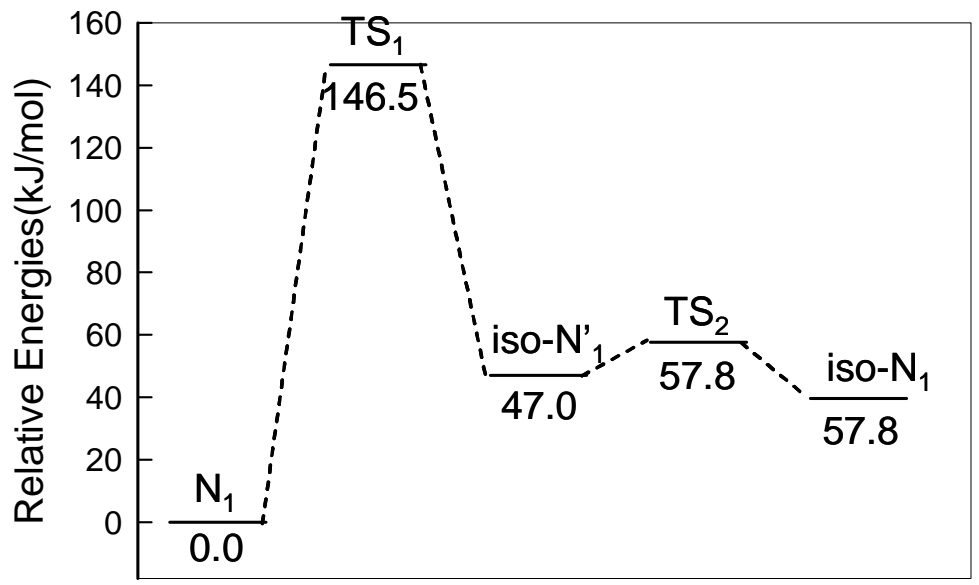

Figure S2 Potential energy surface for the isomerization of nitrone 


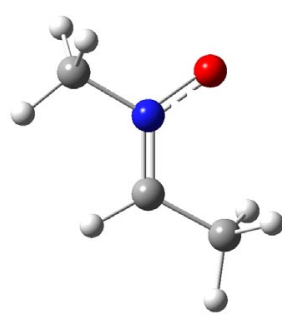

m- $\mathrm{N}_{2}$

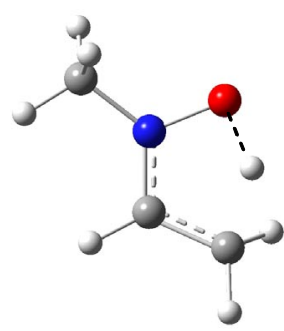

m-TS

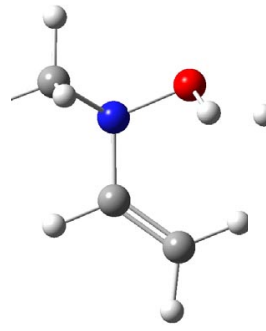

iso- $\mathrm{m}-\mathrm{N}_{2}{ }_{2}$

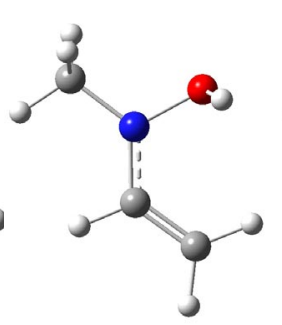

$\mathrm{m}-\mathrm{TS}_{2}$

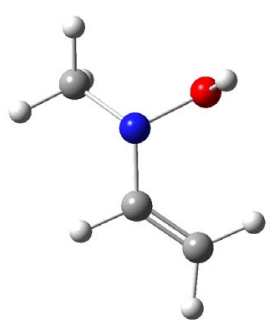

iso-m- $\mathrm{N}_{2}$

Figure S3 Optimized structures of N-methyl-nitrone $\left(\mathrm{m}-\mathrm{N}_{2}\right)$, transition states $\left(\mathrm{m}-\mathrm{TS}_{1}\right.$ and $\left.\mathrm{m}-\mathrm{TS}_{2}\right)$ and its hydroxylamine tautomers (iso- $\mathrm{m}-\mathrm{N}_{2}^{\prime}$ and iso-m- $\mathrm{N}_{2}$ )

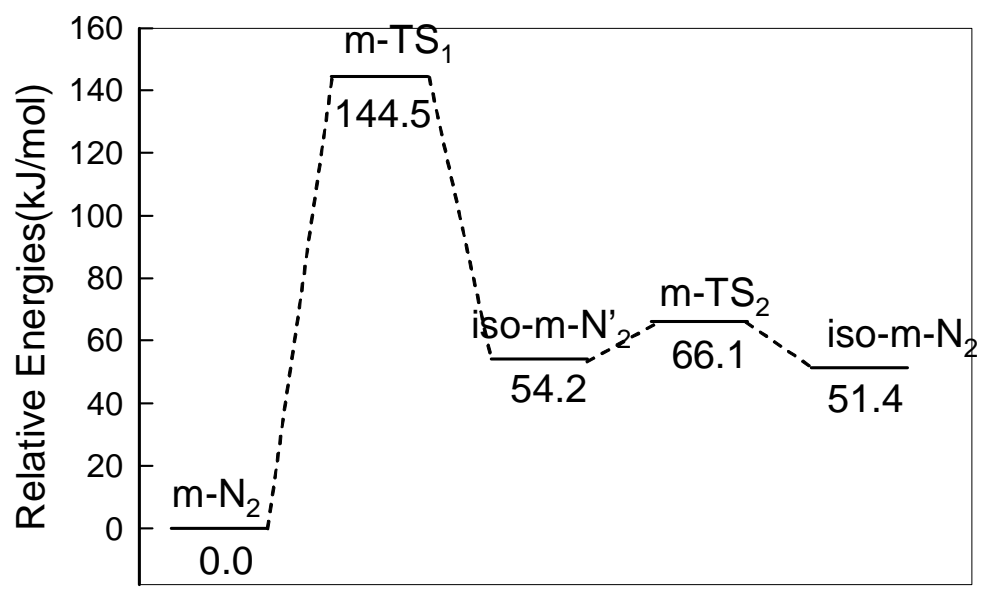

Figure S4 Potential energy surface for the isomerization of N-methyl-nitrone 